\title{
Presentation of CMV Immediate-Early Antigen to Cytolytic T Lymphocytes Is Selectively Prevented by Viral Genes Expressed in the Early Phase
}

\author{
Margarita Del Val, Konrad Münch, \\ Matthias J. Reddehase, and Uirich H. Koszinowski \\ Department of Virology \\ University of UIm \\ P.O. Box 4066 \\ D-7900 Ulm \\ Federal Republic of Germany
}

\section{Summary}

The regulation of antigen processing and presentation to MHC class I-restricted cytolytic T Iymphocytes was studied in cells infected with murine cytomegalovirus. Recognition by cytolytic $T$ lymphocytes of the phosphoprotein pp89, the immunodominant viral antigen expressed in the immediate-early phase of infection, was selectively prevented during the subsequent expression of viral early genes. The surface expression of MHC class I glycoproteins and their capacity to present externally added pp89-derived antigenic peptides were not affected. Because recognition of several other antigens occurred during the early phase, a general fallure in processing and presentation was excluded. Since neither rate of synthesis, amount, stability, nor nuclear transport of pp89 was modified, the failure in recognition indicates a selective interference with pp89 antigen processing and presentation.

Introduction

Recognition of antigens by $T$ lymphocytes requires their presentation by glycoproteins encoded in the major histocompatibility complex (MHC), a phenomenon referred to as MHC restriction (Schwartz, 1985). It is assumed that, after synthesis in infected cells, viral protein antigens have to be processed to yield peptides that, after binding to the MHC-encoded glycoproteins expressed in those cells, are presented at the cell surface to the T cell receptor. Processing is a poorly understood event that appears to involve limited proteolytic degradation (Shimonkevitz et al., 1983; Townsend et al., 1985). Antigens presented by MHC class II molecules are processed in low-pH endosomes, whereas antigens synthesized within the cell and presented by MHC class I molecules seem to be processed at a so far unknown, yet different, cyloplasmic site (Braciale et al., 1987; Germain, 1986, 1988). The location at which the physiological association of antigens with MHC class I molecules takes place is not known either, but it has been shown that externally added antigenic peptides can be presented at the cell surface (Townsend et al., 1986).

Viruses can interfere with antigen presentation by affecting the surface expression of cell membrane proteins required for the recognition of infected cells by cytolytic $T$ lymphocytes (CTLs). For several viruses (Gooding, 1982; Bernards et al., 1983), including herpesviruses (Jennings et al., 1985; Masucci et al., 1987), defective antigen recognition has been associated with decreased surface levels of MHC class I glycoproteins. For adenoviruses, there is evidence that the underlying mechanism is an active interference with class I mRNA processing (Vaessen et al., 1987) or with glycosylation (Burgert and Kvist, 1985). A correlation of these findings with tumorigenicity and evasion of adenoviruses and SV40 from the immune response (Gooding, 1982; Bernards et al., 1983; Tanaka et al., 1985) is a matter of controversy (Haddada et al., 1988). For Epstein-Barr virus, evasion from host-cellular immunity has been suggested to result from the establishment of a latent infection in cells that, owing to very low surface levels of accessory adhesion molecules, constitute poor targets for antiviral CTLs (Gregory et al., 1988). As expected, and as actually shown for class I molecules (Yewdell et al., 1988), the reduction in the surface levels of cell membrane proteins required for antigen presentation and target cell recognition by CTLs indiscriminately prevents efficient recognition of any antigen.

Previous observations made with murine cytomegalovirus (MCMV) infection suggest the existence of an interference of viral gene products with antigen processing and presentation that is not mediated through a modulation in the expression of MHC class I molecules. In permissive cells, cytomegalovirus (CMV) gene expression is regulated in a cascade fashion characteristic of herpesviruses (Stinski, 1983). Proteins expressed in the immediate-early (IE) phase of infection, such as the nonstructural regulatory phosphoprotein pp89, which is encoded by MCMV gene iel (Keil et al., 1985, 1987; Koszinowski et al., 1986), are required for the subsequent expression of early-phase genes, which, after onset of DNA replication, are followed by late-phase genes. IE proteins also represent antigens recognized by the majority of antiviral CTLs (Reddehase and Koszinowski, 1984; Reddehase et al., 1984; Koszinowski et al., 1987; Borysiewicz et al., 1988). Vaccination of mice with the recombinant vaccinia virus MCMV-ielVAC, which expresses pp89 as the only MCMV gene product (Volkmer et al., 1987), sensitizes CD8+ T lymphocytes that protect mice against lethal challenge with MCMV (Jonjic et al., 1988). The Ld-restricted CTL clone IE1 lyses cells that selectively synthesize IE proteins (Reddehase et al., 1986a) and is specific for a peptide of pp89 (Del Val et al., 1988; Reddehase et al., 1989). Clone IE1 also recog. nizes pp89 when it is synthesized again during the late phase of infection, whereas, even though pp89 is present throughout the virus replication cycle, no recognition takes place during the early phase (Reddehase et al., 1986b). Because these experiments did not reveal any alteration in MHC class I expression, an as yet unknown mechanism that prevents pp89 antigen presentation to CTLs must be postulated to operate during the early phase.

In this article we describe that MCMV gene products interfere in a very selective way with the posttranslational steps of processing and presentation of pp89 for recogni- 


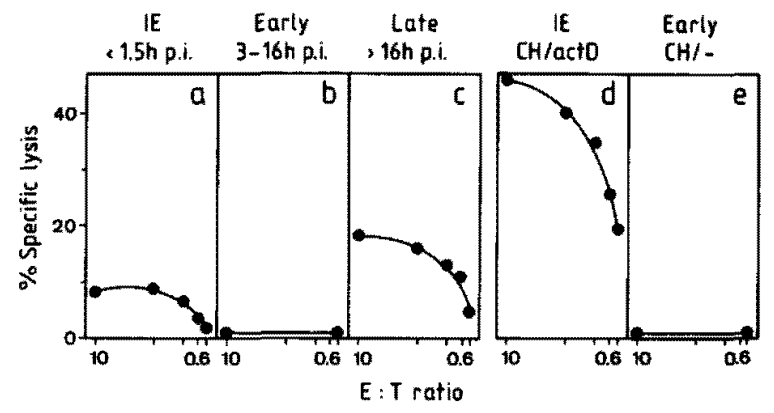

Figure 1. Stage-Specific Recognition of MCMV-Infected Cells by the pp89-Specific CTL Clone IE1

Recognition by clone IE1 of ${ }^{51} \mathrm{Cr}$-labeled MCMV-infected MEF targets was tested in a cytolytic assay using graded numbers of effector CTLS. Infection conditions were as follows: (a) after $1.5 \mathrm{hr}$ of infection, actinomycin $D$ (act D) was added to prevent early gene expression and thus to achieve nonenhanced, selective IE protein synthesis; (b) cells were assayed at $3,5,8,12$, or $16 \mathrm{hr}$ p.i. during the early phase of infection (summary of data); (c) cells were assayed at $24 \mathrm{hr}$ p.i. during the late phase of infection; (d) infection was performed in the presence of cycloheximide $(\mathrm{CH})$, which was replaced after $3 \mathrm{hr}$ by act $\mathrm{D}$ to achieve enhanced and selective IE protein synthesis; (e) infection was performed in the presence of $\mathrm{CH}$, which was removed after $3 \mathrm{hr}$, resulting in enhanced IE gene expression concomitant with early gene expression. In (a), (d), and (e), the cytolytic assay started at $7 \mathrm{hr}$ p.l. E.T ratio, ratio of IE1 effector cells to target celis.

tion by MHC class I-restricted CTLs. Unlike the inhibitory mechanisms mentioned above, the surface levels of MHC class I molecules, as well as their capacity to present both externally added and other endogenously synthesized viral antigens, remain unaffected. The data demonstrate that the three conditions regarded as essential and sufficient for target cell formation, namely, the presence of a sufficient amount of an antigenic protein, the functional integrity of general processing mechanisms, and the presence of MHC molecules capable of presenting antigens, do not guarantee the recognition of that antigen by CTLS. These findings thus reveal the existence of hitherto unknown mechanisms regulating antigen processing and presentation.

\section{Results}

Transition to the Early Phase of MCMV Gene Expression Prevents Presentation of the IE Protein pp89 to CTL Clone IE1

The kinetics of the expression of the MCMV IE protein pp89 in permissively infected mouse embryo fibroblasts (MEFs) have been determined previously (Keil et al., 1984, 1985; Reddehase et al., 1986b). Gene iel encoding pp89 (Keil et al., 1987) is transcribed during the IE phase of viral gene expression, becomes silent during the early phase, and is transcribed again during the late phase. The synthesis of pp89 and the recognition of infected MEFs by the Ld-restricted pp89-specific CTL clone IE1 also follow essentially these kinetics (Figures 1a-1c; Reddehase et al., 1986b). Specifically, infected cells are not recognized when virus gene expression proceeds into the early phase. This result was obtained when cells were arrested

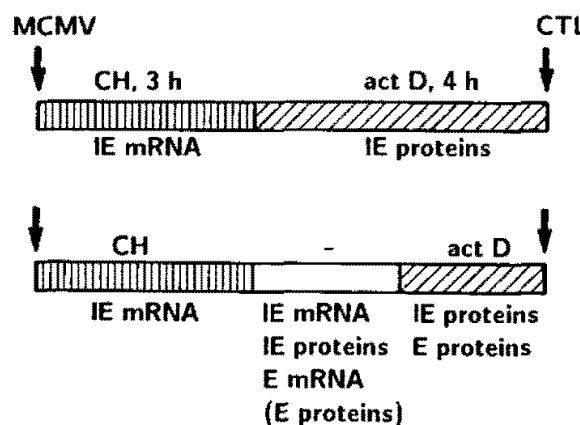

Figure 2. Experimental Design

(Top) Infection of cells in the presence of the protein synthesis inhibitor CH results in enhanced transcription of IE genes, including gene $i \theta$ l encoding pp89. After replacement of $\mathrm{CH}$ by the inhibitor of transcrip. tion act $D, I E$ mANA is translated, leading to enhanced and selective IE protein synthesis and to enhanced recognition of IE antigens by CTLs 4 hr later (Reddehase et al., 1984).

(Bottom) If act $\mathrm{D}$ is not added immediately after removing $\mathrm{CH}$, but at later time points, the synthesized IE proteins activate the transcription of early $(E)$ genes. The duration of $E$ gene transcription is defined by the time at which act $D$ is added. Translation of early mRNAs leads to the synthesis of $\mathrm{E}$ proteins. With this protocol, conditions of limited $\mathrm{E}$ gene expression after enhanced IE gene expression are achieved.

in the early phase by performing the infection in the presence of phosphonoacetic acid (PAA) and tested $24 \mathrm{hr}$ after infection (Reddehase et al., 1986b), and also when they were tested at different times during the early phase (data for $3,5,8,12$, and $16 \mathrm{hr}$ postinfection [p.i.] are jointly shown in Figure 1b). The fact that infected cells were no longer recognized by clone IE1 after only $3 \mathrm{hr}$ of permissive infection suggested that viral gene products expressed during the early phase negatively affected the presentation of pp89.

Because the rate of pp89 synthesis is low in the physiological IE phase, infection was performed in the presence of cycloheximide $(\mathrm{CH})$ to prevent translation, which results in an accumulation of IE transcripts. Enhanced and selective synthesis of IE proteins, the most abundant of which is pp89, is then accomplished by replacing $\mathrm{CH}$ by actinomycin D (act D), which causes release from the translation block while preventing the transcription of early genes (see experimental design in Figure 2, top; Reddehase et al., 1986b). Under these conditions the synthesis of pp89 continues for at least $8 \mathrm{hr}$ without detectable decline (Keil et al., 1985), and the recognition of the cells by clone IE1 is markedly increased (Figure 1d; Reddehase et al., 1984). If, however, the transition to early gene expression is not blocked by act $\mathrm{D}$ after the removal of $\mathrm{CH}_{3}$ the synthesis of pp89 from the accumulated IE transcripts declines with time (Keil et al., 1985) and the cells no longer constitute targets for clone IE1 (Figure 1e). These results demonstrate the following: first, transition to the early phase, which shuts off IE translation, also prevents the expression of the antigenic determinant of pp89 defined by clone IE1; second, this prevention is posttranscriptional; and third, it cannot be overcome by enhancing the transcription of IE genes.

Since pp89 can be detected with specific antibodies 


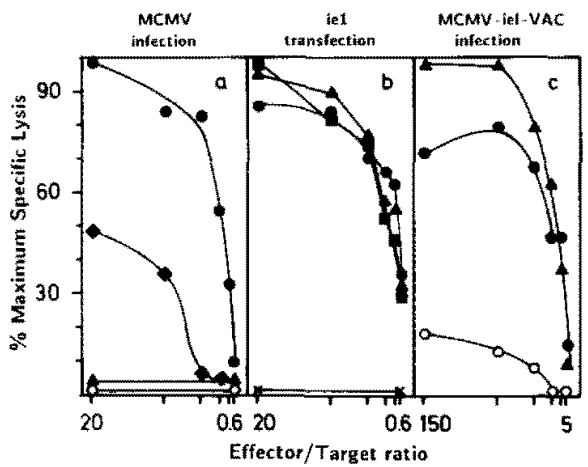

Figure 3. Transition to the MCMV Early Phase Prevents Presentation of pp89 to CTL Clone IE1

Recognition of pp89 was tested in a cytolytic assay using the pp89. specific CTL clone IE1 ( $a$ and b) or MCMV-specific polyclonal CTLs (c) as effector cells. The target celis were prepared as follows: (a) MEFs were infected with MCMV in the presence of $\mathrm{CH}$ for $3 \mathrm{hr}$. After removal of $\mathrm{CH}$, act $\mathrm{D}$ was added either immediately (O), $20 \mathrm{~min}(\$)$, or $45 \mathrm{~min}$ (A) later, as explained in Figure 2. Uninfected inhibitor-treated cells were used as a control (O) (b) Lie1-L transfectants, expressing pp89 constitutively, were treated for $3 \mathrm{hr}$ with $\mathrm{CH}$. After removal of $\mathrm{CH}$, act $D$ was added immediately (O) or after $45 \mathrm{~min}(\boldsymbol{A})$. Controls included Lie1 $L^{d}$ cells not incubated with metabolic inhibitors $(G)$ and $L L^{d}$ cells that do not contain viral genes $(x)$. (c) MEFs were infected with MCMVie/VAC in the presence of $\mathrm{CH}$. Following removal of $\mathrm{CH} 3 \mathrm{hr}$ later, act $\mathrm{D}$ was added immediately (O) or after $45 \mathrm{~min}$ (A). As a control, cells infected with wild-type vaccinia virus and treated with the metabolic inhibitors were used (O). In all cases, the cytolytic assay started $7 \mathrm{hr}$ after addition of $\mathrm{CH}$ to target cells. Mean values of specific Iysis are normalized for the maximum lysis obtained within each group (40\% for [a], $30 \%$ for [b], and $24 \%$ for [c]).

throughout the early phase, the data were thus far consistent with the interpretation that recognition of the antigen by clone IE1 correlated with the synthesis of pp89 rather than with its presence (Reddehase et al., 1986b). The early phase lasts about $16 \mathrm{hr}$, during which transcription from the entire $235 \mathrm{~kb}$ genome, involving a high number of genes, is detected (Keil et al., 1984). None of these genes is defined as yet. Viral functions that cause the shutoff of pp89 synthesis and those that prevent the presentation of the IE1 determinant may be specitied by the same gene or by different genes. in addition to early gene functions, an autoregulatory role of pp89 in antigen presentation has to be considered.

To dissect these events, the experimental regimen explained in Figure 2 (bottom) was employed: by adding act D not immediately after removal of $\mathrm{CH}$ but at defined time points later, a variable period permissive for early gene transcription was set. With this approach it was determined that an interval of 20 min of early gene transciption was sufficient to diminish the presentation of the pp89 antigen, and that an interval of $\mathbf{4 5}$ min completely interfered with it (Figure 3a). It has been demonstrated that pp89 can activate the transcription of cellular genes such as c-fos (Schickedanz et al., 1988). During the interval permissive for early gene transcription, the pp89 synthesized in the absence of act $D$ could activate the transcription not only of viral early genes but also of cellular genes. Therefore, the possibility had to be considered that the inhibitory effect on pp89 antigen presentation was caused by cellular proteins induced by pp89. The same schedule of treatment with the metabolic inhibitors of the transtectant cell line Lie1-Ld, which expresses pp89 constitutively, as well as of MEFs infected with the recombinant virus MCMV-ielVAC, which expresses pp89 only upon infection, and both of which lack MCMV early genes, did not prevent or reduce lysis by CTLs (Figures $3 \mathrm{~b}$ and $3 \mathrm{c}$ ). These controls thus excluded the possibility that cellular proteins induced by pp89 itself or by related proteins translated from splicing derivatives in transcription unit ie1 (Koszinowski et al., 1987) were responsible for the failure in pp89 antigen expression. In conclusion, the function that interferes with processing and presentation of the pp89 antigen is based on viral genes expressed in the first $\mathbf{4 5}$ min after transition to the early phase.

\section{Inhibition of pp89 Antigen Presentation and of pp89 Synthesis Are Separate Events}

pp89 is not a structural component of the virus particle; therefore, its synthesis in infected cells is required for recognition by pp89-specific CTLs. It was an open question whether the genes expressed during the first 45 min of the early phase, which abrogate pp89 antigen presentation, also caused the shutoff of pp89 synthesis or whether this effect was specified by genes expressed at later times during the prolonged early phase. To this end, protein synthesis after periods of $\mathbf{2 0}$ and $\mathbf{4 5}$ min of early gene transcription was analyzed by pulse-labeling and immunoprecipitation at 5, 7, and $9 \mathrm{hr}$ p.i., i.e., after 2,4 , and $6 \mathrm{hr}$ of translation. No difference was found at any time tested in the rate of synthesis of pp89 between cells expressing only IE genes (Figure 4A, lane b) and those that also express early genes (lanes $c$ and d). Shown are only the data for $9 \mathrm{hr}$ p.i., the time point that coincides with the end of the cytolytic assay. Posttranslational conversion of pp89 to pp76, which is mediated by cellular proteases (Keil et al., 1985), was not altered either. The only difference detected after immunoprecipitation between cells lysed by CTL clone IE1 (lane b) and those not recognized was the additional presence of early proteins (marked with $E$ in Figure $4 A$, lanes $c$ and d). These results indicated that the genes that negatively affect pp89 synthesis are not transcribed during the first $\mathbf{4 5} \mathrm{min}$ of the early phase. It is worth noting that in spite of a significantly lower rate of pp89 synthesis in L/iet-Ld transfectants (lane e), these cells are efficiently recognized by CTLs. The experimental dissection of the interference with pp89 antigen presentation and the down-regulation of pp89 synthesis proved that these are separate events operating at different times during the early phase. In addition, it was concluded from these data that the inhibitory effect on pp89 antigen presentation operates posttranslationally.

\section{Expression of the First MCMV Early Genes Does Not Affect Amount, Stability, or Nuclear Transport of pp89}

Deficient presentation to CTLs of stable influenza virus proteins expressed in recombinant vaccinia virus-infected cells has been shown recently to be overcome by constructing modified proteins with a reduced half-life 
A

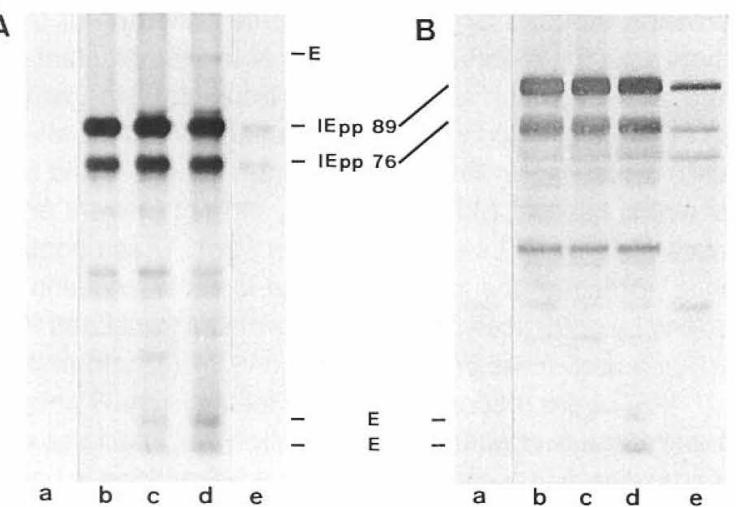

Figure 4. Expression of the First MCMV Early Genes Does Not Affect the Rate of pp89 Synthesis, the Posttransiational Conversion to $\mathrm{pp} 76$, or the Amount of pp89

(A) The rate of synthesis of $\mathrm{pp} 89$ was measured by metabolic labeling of infected cells with ${ }^{35}$ S ]methionine for 20 min starting at $9 \mathrm{hr}$ p.i., followed by immunoprecipitation of cell lysates with anti-MCMV serum and polyacrylamide gel electrophoresis. Positions of the IE proteins pp89 and pp76 and of early proteins $(E)$ are indicated. Lane $a$, uninfected MEFs. Lane b, MEFs infected with MCMV under enhanced and selective IE conditions ( $\mathrm{CH}$ and act $\mathrm{D}$ treatment). Lane $\mathrm{C}$, MEFs that were infected in the presence of $\mathrm{CH}$ were incubated for $20 \mathrm{~min}$ in the absence of metabolic inhibitors before act $D$ was added. Lane $d$, same as lane $c$ but with a $45 \mathrm{~min}$ incubation without inhibitors. Lane e, L/ie1Ld transfectants.

(B) Amount of pp89 detected by Western blot of the cell lysates described in (A), lanes a-e, using the same antiserum as in (A).

(Townsend et al., 1988). This further strengthened the idea that processing of an antigen involves proteolytic degradation (Townsend et al., 1985, 1986). Following this reasoning, an increased stability of pp89 during the early phase could offer an explanation for the observed lack of recognition by CTLS. On the other hand, a different cleavage pattern of pp89 during the early phase might lead to the destruction of the epitope recognized by CTLs, and this would also result in a failure of antigen presentation. Therefore, the stability of pp89 during the IE and early phases was compared.

As a first step, the amount of pp89 synthesized after release from the $\mathrm{CH}$ block and present in infected cells at 5,7 , and $9 \mathrm{hr}$ p.i. was measured by Western blot analysis in cells expressing only IE proteins and in cells also expressing early proteins. As shown in Figure 4B for $9 \mathrm{hr}$ p.i., the amount of IE proteins was the same regardless of whether early genes were expressed (compare lane $b$ with lanes $\mathrm{c}$ and d) and was clearly higher in infected (lanes b-d) than in transfected cells (lane e). As a second step, the stability of pp89 under IE and early conditions was measured by pulse-labeling with [ ${ }^{35}$ S]methionine at $3 \mathrm{hr}$ p.i. followed by a period of chase in the absence of radioactive precursor (Figure 5). With the aim of identifying the relevant protein fragments containing the IE1 epitope, an antiserum raised against the 19 amino acid peptide of pp89 that contains this epitope (Del Val et al., 1988) was used for immunoprecipitation. Even though efficiently presented to CTLs, pp89 synthesized in the IE phase represents a very stable protein, since most of the labeled

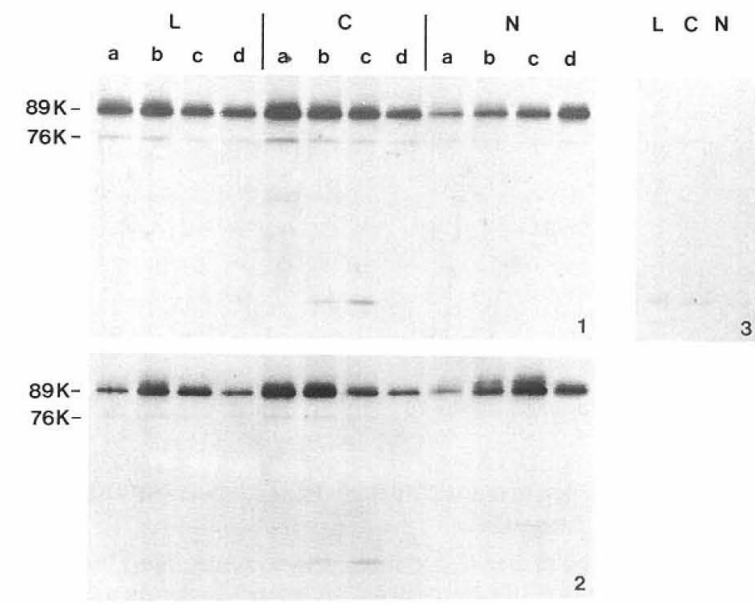

Figure 5. Stability and Nuclear Transport of pp89 Are Not Affected by MCMV Early Gene Expression

MEFs were infected in the presence of $\mathrm{CH}$. After removal of $\mathrm{CH}$ at 3 hr p.i., act $D$ was added either immediately (1) or after $45 \mathrm{~min}$ (2). Uninfected cells treated as in (1) were used as a control (3). Cells were labeled for 30 min with ${ }^{35}$ S]methionine immediately after $\mathrm{CH}$ removal and then washed with an excess of unlaieled methionine. Whole-cell lysates $(L)$ or cytoplasmic $(C)$ and nuclear $(N)$ fractions were prepared immediately (lanes a) and 3, 6, and $12 \mathrm{hr}$ later (lanes b, c, and d, respectively). Immunoprecipitation was performed with a rabbit antiserum against peptide $P(161-179)$, which contains the epitope recognized by CTL clone IE1 in pp89. Samples were analyzed by polyacrylamide gel electrophoresis. Positions of pp89 and pp76 and indicated.

pp89 was still detectable in the cell lysates even after 12 hr of chase (Figure 5, 1L, lanes a-d). The same stability was observed for $\mathrm{pp} 89$ when transcription was allowed for 45 min (Figure 5, 2L, lanes a-d). Low amounts of proteins smaller than pp89 that contained the IE1 epitope were detected. These might represent either degradation products or proteins related to $p p 89$ and arising by differential splicing from transcription unit ie1, which encodes pp89 (Keil et al., 1984, 1985). The protein pattern was the same under IE or early conditions, and was also identical with the one detected when, instead of the epitope-specific antiserum, antiserum directed against the whole protein was used (data not shown), thus giving no indication of a selective destruction of the IE1 epitope. However, relevant fragments of small size or very low abundance may have passed undetected. The same results were obtained when radioactive labeling was performed at $6 \mathrm{hr}$ p.i. (data not shown). Altogether, these findings demonstrated that MCMV early gene expression was not associated with an altered stability of pp89.

After synthesis, pp89 migrates into the nucleus, where it activates transcription (Koszinowski et al., 1986). From a deletion mutant of pp89 that lacks the nuclear transport signal and is therefore confined to the cytoplasm, it is known that migration of pp89 into the nucleus is not required for recognition by CTLs $(H$. Volkmer and M. D. V., unpublished data). This finding is in accordance with the widely accepted idea (Germain, 1988) that processing of endogenously synthesized antigens takes place in a cytoplasmic compartment. On the other hand, enhanced 


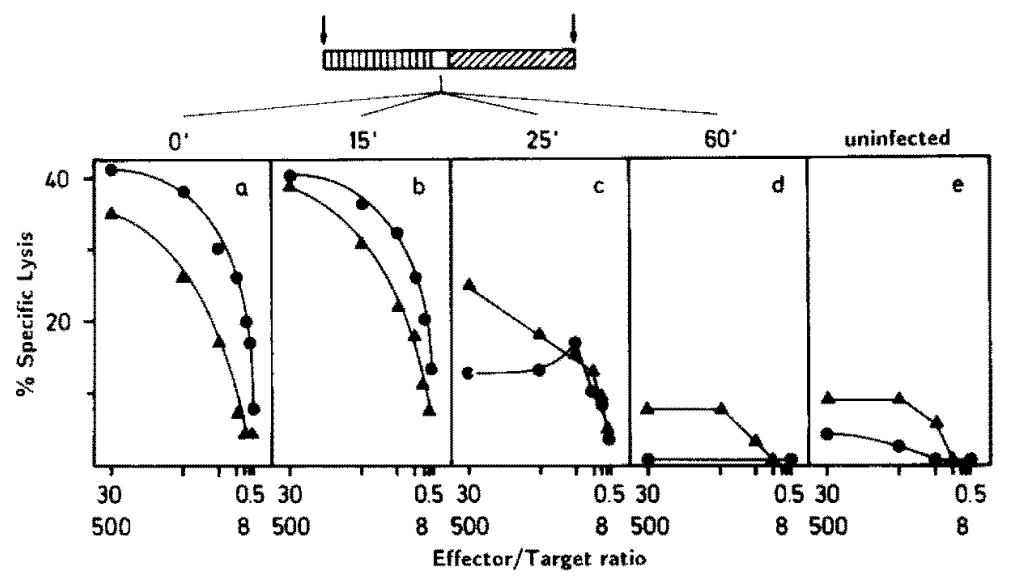

Figure 6. Transition to the Early Phase Abrogates Recognition of pp89 by Specific BALB/C Polyclonal CTLS

Recognition of pp89 was tested in a cytolytic assay using as effector cells the CTL clone IE1 (effector to target cell ratios from 30:1 to 0.5:1) (C) or pp89-specific polyclonal CTLS (effector to target cell ratios from 500:1 to B:1) (A). For the preparation of target cells, MEFs were infected with MCMV in the presence of $\mathrm{CH}$ which was removed after $3 \mathrm{hr}$. Act D was then added either immediately (a) or after 15 (b) 25 (c), or 60 (d) $\mathrm{min}$, as explained in Figure 2. The assay was performed at $7 \mathrm{hr}$ p.l. Uninfected cells treated as in (a) were used for control (e). transport of pp89 into the nucleus during the early phase might result in a withdrawal of pp89 from cytoplasmic antigen-processing pathways. The rate of nuclear transport of pp89 was therefore measured by tracing the labeled protein in the nuclear and cytoplasmic fractions of infected cells. With increasing periods of chase, the amount of labeled pp89 gradually decreased in the cytoplasm and was localized to the nuclear fraction (Figure 5, C and N). No influence of early gene expression on the rate of nuclear transport could be detected (Figure 5, compare $1 \mathrm{C}$ and $1 \mathrm{~N}$ with $2 \mathrm{C}$ and $2 \mathrm{~N}$ ), thus excluding an enhanced nuclear trapping of pp89 as an explanation for the failure in pp89 antigen presentation during the early phase.

In summary, neither a general enhancement of pp89 stability, nor a detectable selective loss of the epitope, nor a different nuclear/cytoplasmic compartmentalization of the protein can account for the lack of pp89 antigen presentation to CTLs in the early phase.

\section{The Fate of the IE1 Epitope Reflects the Recognition of pp89 by BALB/c Polyclonal CTLS}

The data presented so far showed that the particular epitope of pp89 defined by clone IE1 was no longer detectable when viral gene expression proceeded into the early phase. To study whether the fate of this epitope was representative of the recognition of all pp89 epitopes, pp89 presentation to BALB/c pp89-specific polyclonal CTLs was analyzed. By using MCMV-iel-VAC for in vivo sensitization, pp89-specific polyclonal CTLs were generated that recognized cells arrested in the IE phase of MCMV infection (Figure 6a). Transition into the early phase prevented recognition of pp89 by these polyclonal CTLs with kinetics indistinguishable from those observed for cione IE1 (Figures 6b-6d). In addition, it was found that pp89specific polyclonal CTLs did not lyse infected fibroblasts of the mutant strain BALB/C-H-2dm2, in which the $\mathrm{L}^{d}$ gene is deleted (Table 1B). These results demonstrated that recognition of pp89 by BALB/c polyclonal CTLs was entirely restricted through $L d$, the same class I molecule that serves as the antigen-presenting molecule for clone IE1.
In conclusion, the epitope recognized by clone IE1 truly reflected the recognition pattern of $p p 89$ by polyclonal BALB/C CTLS.

Surface Expression and Functional Integrity of the MHC Class I Molecule Ld during the Early Phase

For recognition by CTLs of viral antigens synthesized in an infected cell, antigenic peptides have to be presented by $\mathrm{MHC}$-encoded class I glycoproteins. Interference with the cell surface expression of class I molecules can dimin. ish or even abolish recognition by CTLs. Cytofluorometric determination of the surface expression of the MHC class I molecules $K^{d}, D^{d}$, and $L^{d}$ revealed no differences between celis that selectively synthesized IE proteins (Figure $7 \mathrm{~A}$, top panel), cells with restricted expression of early genes (center panel), and uninfected celis (bottom panel). When $L^{d}$ served as a target antigen in a cytolytic assay using the Ld-specific CTL clone B6aLd, no differences in target cell susceptibility to lysis were seen either (Figure $78)$. It was thus concluded that inhibition of pp89 presentation was not associated with alterations in the surface expression of class I molecules.

Yet, these results did not exclude an alteration in the function of the class I molecules to serve as antigenpresenting molecules. It has been proposed that incubation of target cells with peptides circumvents the intracellular steps of processing, since it leads to target cell recognition by CTLs (Townsend et al, 1986). The synthetic nonapeptide YPHFMPTNL (one-letter code), which is deduced from the pp89 sequence, represents the optimal antigenic peptide for CTL clone IE1 (Reddehase et al., 1989). Incubation with this nonapeptide of cells that expressed MCMV early genes and did not present endogenously synthesized pp89 revealed that these cells were still able to present the externally added nonapeptide (Figure $7 \mathrm{C}$, center panel). Identical results with the suboptimal heptapeptide PHFMPTN confirmed this conclusion (data not shown). Therefore, the block in pp89 presentation was caused neither by an alteration in the cell surface expression of $L^{d}$ nor by a defect in its function to present antigenic peptides. 


\begin{tabular}{|c|c|c|c|c|c|c|c|}
\hline & \multirow{2}{*}{\multicolumn{2}{|c|}{$\begin{array}{l}\text { Genes Expressed } \\
\text { in Target Cells }\end{array}$}} & \multicolumn{5}{|l|}{ CTLs } \\
\hline & & & \multirow{2}{*}{$\begin{array}{l}\text { Clone } \\
\text { IE1 }\end{array}$} & \multirow{2}{*}{$\begin{array}{l}\text { Polyclonal } \\
\text { Anti-pp89 }\end{array}$} & \multirow{2}{*}{$\begin{array}{l}\text { Clone } \\
\text { E1 }\end{array}$} & \multirow{2}{*}{$\begin{array}{l}\text { Clone } \\
\mathrm{E2}\end{array}$} & \multirow{2}{*}{$\begin{array}{l}\text { Polyclonal } \\
\text { Anti-MCMV }\end{array}$} \\
\hline & $M H C^{*}$ & MCMV† & & & & & \\
\hline \multirow[t]{3}{*}{ A. } & $K^{d} D^{d} L^{d}$ & IE phase & $40 \$$ & 59 & 0 & 0 & 48 \\
\hline & $K^{d} D^{d} L^{d}$ & $I E+E$ phase & 1 & 7 & $\underline{60}$ & $\underline{40}$ & 74 \\
\hline & $K^{d} D^{d} L^{d}$ & - & 0 & 0 & 0 & 0 & 3 \\
\hline \multirow[t]{3}{*}{ B. } & $K^{d} D^{d}$ & IE phase & 0 & 4 & 1 & 0 & 20 \\
\hline & $K^{d} D^{d}$ & $I E+E$ phase & 0 & 0 & 4 & 0 & 38 \\
\hline & $K^{d} D^{d}$ & - & 0 & 0 & 0 & 0 & 5 \\
\hline \multirow[t]{2}{*}{ c. } & $\mathrm{L}^{d}$ & EcoRI F & 0 & ND & 29 & 0 & ND \\
\hline & $L^{d}$ & - & 0 & ND & 7 & 0 & ND \\
\hline \multirow[t]{3}{*}{ D. } & $K^{b} D^{b}$ & IE phase & 0 & 21 & 0 & ND & 25 \\
\hline & $K^{b} D^{b}$ & $I E+E$ phase & 0 & 9 & 0 & ND & 32 \\
\hline & $K^{b} D^{b}$ & - & 0 & 8 & 0 & ND & 8 \\
\hline
\end{tabular}

\footnotetext{
* Target cells: MEFs from BALB/c mice (A), BALB/c-H-2dm2 mice (B), or C57BL/6 mice (D). L/Lo cells were transfected with fragment EcoRI F from MCMV DNA (C).

$\dagger$ Infection conditions: IE phase, enhanced and selective IE expression, as described in Figure 2, top. IE + E phase, infection performed in the presence of PAA to prevent late-phase gene expression.

$\mp C T L$ clones were derived from BALB/C $\left(H-2^{\circ}\right)$ mice. Polyclonal CTLs were obtained either from BALB/c mice (for $A$ and $\left.B\right)$ or from $C 57 B L / 6\left(H-2^{b}\right)$ mice (for D).

$\$$ Percentages of specific lysis obtained at effector to target cell ratios of 20:1 (for CTL clones) or 100:1 (for polyclonal CTLs).

" Underlined are results that revealed the presentation of viral antigens other than pp89 during the early phase of the MCMV replication cycle. ND, not done.
}

\section{Selectivity of the Negative Regulation of pp89} Antigen Processing and Presentation

From all these findings it can be concluded that the interference with pp89 antigen expression involved the poorly defined intracellular steps of the antigen-processing and -presentation pathways. To study whether this negative regulation is selective for pp89 or concerns antigen presentation in general, the effect on the presentation of other MCMV antigens expressed concomitantly with pp89 was analyzed (Table 1). To this end, CTLs derived from infected mice were cloned and screened for recognition of cells infected with MCMV in the presence of PAA. Viral gene expression in such cells is restricted to IE and early genes, and, although they are not recognized by CTL clone IE1, they constitute targets for polyclonal MCMVspecific CTLs (Reddehase et al., 1984). With this approach, two new CTL clones were established, E1 and E2, both of which recognized MCMV early antigens since they were able to lyse cells infected in the presence of PAA but did not recognize cells infected under IE conditions (Table 1A). Antigen recognition by both clones was restricted through $L^{d}$, since no lysis of infected BALB/C-H-2dm2 cells, which lack $L^{d}$, was detected (Table 1B). CTL clone E1, but not clone $E 2$, recognized $L / L^{d}$ cells transfected with the EcoRI F fragment of MCMV DNA (Ebeling et al., 1983; B. Bühler et al., unpublished data), which indicated that these two CTL clones have different antigen speciticities (Table 1C). Lysis of infected cells by clones E1 and E2 was not higher during the late phase than during the early phase (not shown). The objection that presentation of E1 and E2 antigens might also have been inhibited during the early phase, although to a lower extent than pp89, can thus be refuted. Presentation of these two antigens could account for the recognition of early-phase infected cells by polyclonal MCMV-specific CTLs (Table 1A); however, additional viral antigens must be presented during the early phase by the $\mathrm{K}^{\mathrm{d}}$ or $\mathrm{D}^{\mathrm{d}}$ glycoproteins, because BALB/C-H$2^{\mathrm{dm} 2}$ cells infected in the presence of PAA were also recognized by these polycional CTLs (Table 1B). It was therefore concluded that, even though presentation of pp89 to BALB/C CTLs was prevented during the early phase, presentation of at least three other viral antigens, two of them $L^{d}$ restricted, as is pp89 itself, was nevertheless very efficient.

When recognition of MCMV-infected cells by C57BL/6 $\left(\mathrm{H}-2^{\mathrm{b}}\right)$ pp89-specific polyclonal CTLs was analyzed, it was found that, as was the case in the $\mathrm{H}-2^{\mathrm{d}}$ haplotype, presentation of pp89 by $\mathrm{H}-2^{\mathrm{b}}$ class I molecules did occur during the IE phase but was prevented during the early phase (Table 1D). Again, the testing of MCMV-specific polyclonal CTLs revealed further viral antigens presented during the early phase by $\mathrm{H}-2^{b}$ class I molecules (Table 1D).

Collectively, the results summarized in Table 1 demonstrate that the inhibitory effect on pp89 antigen presentation is highly selective, because at least two viral early antigens presented by $L^{d}$, at least one presented by $K^{d}$ or $D^{d}$, and at least one presented by $K^{b}$ or $D^{b}$ were not subject to this inhibition. A general block affecting processing and presentation of all nascent viral antigens in the early phase of MCMV replication was thus excluded.

\section{Inhibition of pp89 Presentation Cannot Be Explained by Antigen Competition} for the Presenting Molecule Ld Competition between different antigens presented by the 


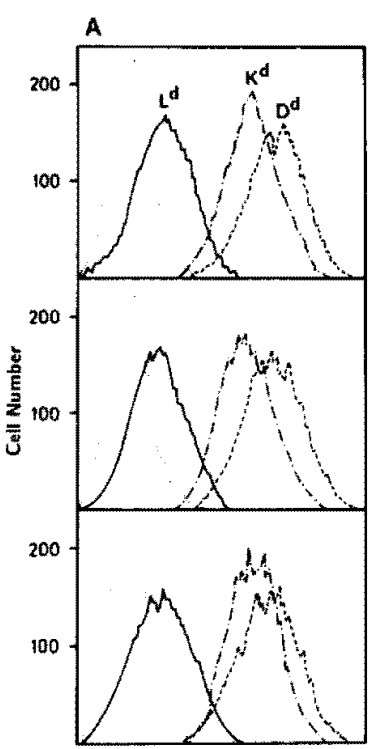

Log Fluorescence lintensity

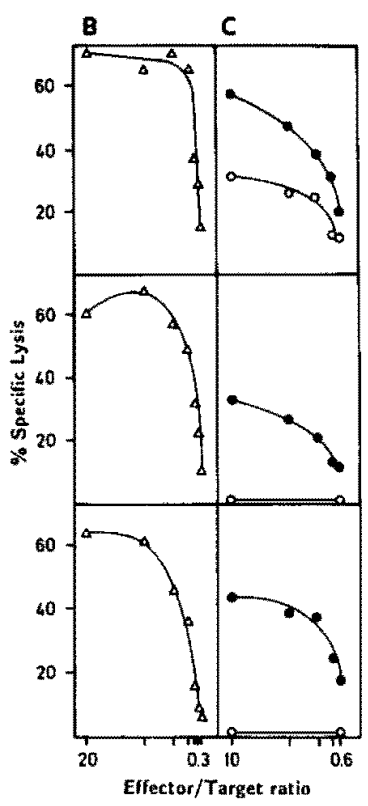

Figure 7. Expression of MCMV Early Genes Does Not Modity the Surtace Levels or the Peptide Presentation Function of MHC Class I Molecules

MEFs were infected under enhanced and selective IE conditions (top paneis) or under conditions in which early transcription was limited to $2 \mathrm{hr}$ (center panels) as explained in Figure 2. Uninfected MEFs treated with the metabolic inhibitors are shown as controls in the bottom panels.

(A) Surfece levels of $\mathrm{H}-2^{\text {d }}$ class 1 molecules were measured by flow cytofluorometry at $7 \mathrm{hr}$ after infection or mock infection on cells labeled with mouse monoclonal antibodies specific for $L^{d}, K^{d}$, and $D^{d}$, as indicated, followed by labeling with fluoresceinated anti-mouse antibody. The dotted lines represent background labeling obtained with the fuoresceinated anti-mouse antibody alone.

(B) Aecognition of surface $L^{d}$ molecules on ${ }^{51} \mathrm{Cr}$-labeled target cells by the Lo-spectfic CTL clone B6aLd.

(C) Presentation of the pp89-derived synthetic peptide YPHFMPTNL after a $1 \mathrm{hr}$ incubation of target cells with $100 \mu \mathrm{M}$ peptide (O), measured in a cylolytic assay using CTL clone IE1 as elfector cells. Control cells not incubated with peptide $(O)$ were also tested.

same MHC class I molecule and recognized by CTLs can be demonstrated with synthetic peptides (Maryanski et al., 1987). In particular, it has been recently shown that peptides derived from the tum- antigen P91A (De Plaen et al., 1988) and pp89-derived peptides, the only two antigenic sequences presented by the $L^{\alpha}$ glycoprotein that have been characterized so far, can mutually compete for $L^{d}$ (Lurquin et al., 1989). During the early phase of infection, when the IE protein pp89 is not presented by $L d$, other antigens are recognized by the $L^{d}$-restricted CTL clones E1 and E2. Competition for the Ld molecule effected by these early antigens could possibly prevent presentation of pp89 during the early phase.

To test this hypothesis, the kinetics of pp89 and E1 antigen expression were analyzed during the transition from the IE to the early phase. The duration of early gene transcription was limited by the addition of act $D$ at different

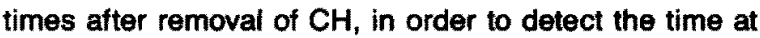
which the early gene encoding the E1 antigen is ex-

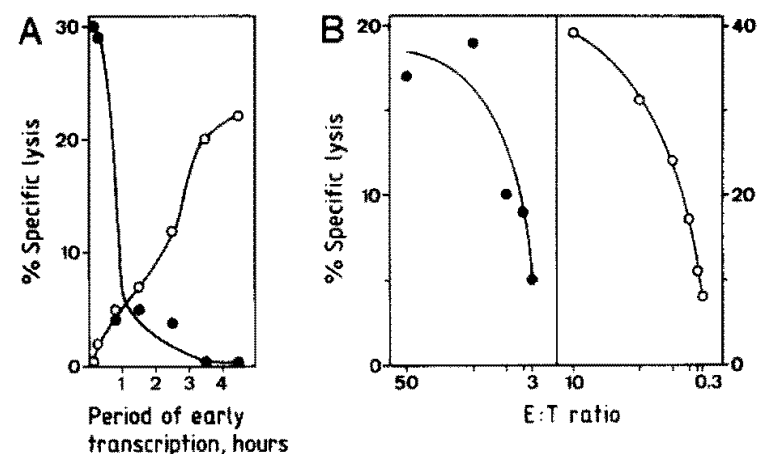

Figure 8. Presentation by $L^{d}$ of the E1 Epitope and of pp89 Can OCcur Simultaneousiy

(A) Kinetics of antigen expression in the transition from the IE to the early phase. MEFs were infected with MCMV in the presence of $\mathrm{CH}$, which was washed out $3 \mathrm{hr}$ later. The time points at which act $D$ was added detine the duration of early gene transcription. In all cases, 8 hr for protein synthesis, antigen processing, and antigen presentation was allowed before the target cels were assayed for recognition by pp89-specitic $L^{d}$-restricted polyclonal CTLs at an effector to target cell ratio (ETT ratio) of $25: 1$ ( ), and by the early-specific $L^{d_{-} \text {-restricted } C T L}$ clone E1 at an ET ratio of 5:1 (O).

(B) Antigen expression in the late phase. MEFs were infected with MCMV at a multiplicity of 2 in the absence of metabolic inhibitors, and tested at $20 \mathrm{hr}$ p.i. with ppo9-specific polyclonal CTLs (C) and with CTL clone $\mathrm{E} 1$ (O).

pressed. The results shown in Figure $8 A$ indicate that 2-4 hr of early gene transcription was required eventually to obtain an amount of E1 antigen sufficient for detection by CTL clone E1. This period of early gene transcription was longer than the period required to prevent pp89 antigen presentation, thus suggesting that E1 peptide competition for $L^{d}$ was unlikely. It could be argued, however, that the amount of E1 peptide required for competition with pp89 is lower than the amount required for target recognition by CTL clone E1. This possibility was excluded by the finding that simultaneous presentation of pp89 and E1 took place in the late phase of the virus replication cycle (Figure $8 \mathrm{~B}$ ). Recognition of infected cells by CTL clone E2 also occurred during the late phase (data not shown). Thus, sufficient amounts of E1 and E2 peptides were present in the late phase to produce a target; nevertheless, they did not exert an inhibitory effect on the presentation of pp89derived peptides.

In summary, the selective prevention of pp89 antigen presentation that occurs during the early phase of the MCMV replication cycle cannot be explained by competition for binding to the $L^{d}$ molecule exerted by the endogenously synthesized viral antigens E1 and E2.

\section{Discussion}

In response to infection with MCMV, BALB/c mice generate protective $T$ lymphocytes of the $\mathrm{CDB}^{+}$subset. These T lymphocytes predominantly recognize antigens synthesized during the IE phase of the viral replication cycle. Vaccination with the recombinant vaccinia virus MCMVIeI-VAC, encoding the major IE protein pp89, renders mice 
resistant to lethal challenge with MCMV. By using both polyclonal and cloned pp89-specific MHC class I (Ld)-restricted CTL lines, regulation of the presentation of pp89 was examined throughout the virus replication cycle. We present evidence for the following: first, similar to MCMV gene expression, which is temporally regulated in three phases - namely, IE, early, and late-processing and presentation of pp89 for recognition by CTLs is under strict control, displaying the same kinetics; second, arrest of the viral replication cascade in the IE phase, as well as selective expression of the isolated gene iel encoding $\mathrm{pp89}$, provide efficient antigen presentation; third, release from the arrest followed by expression of the first viral early genes completely prevents pp89 antigen presentation; fourth, the late phase of gene expression is associated with reinitiation of $\mathrm{pp} 89$ synthesis and release from the interference with antigen presentation; fifth, the interference with pp89 antigen presentation occurs posttranslationally but does not involve alterations in protein amount, stability, or nuclear compartmentalization; sixth, the surface expression and antigen-presenting function of the MHC class I molecule $L^{d}$ are not affected; and seventh, the intervention with pp89 antigen processing and presentation is highly selective in that it does not apply to other MCMV antigens synthesized concomitantly with pp89 in the infected cells and presented by several different class I molecules, including $L$.

This report gives a clear example for a highly selective, temporally regulated, and reversible prevention of viral antigen presentation to class I-restricted $T$ lymphocytes. The results indicate that the interference takes place at an intracellular stage of pp89 antigen processing after translation and before the presentation of antigenic peptides at the cell surface.

Because of its selectivity, the inhibition of pp89 presentation is unlike other reported cases of interference with antigen recognition by CTLs, all of which could be explained by a general decrease in the surface levels of cellular presenting or adhesion molecules (Gooding, 1982; Bernards et al., 1983; Jennings et al., 1985; Masucci et al., 1987; Gregory et al., 1988) that indiscriminately affects the presentation of any antigen.

An observation more closely related to the data presented in this article has been made in recombinant vaccinia virus-infected cells, in which presentation of influenza virus antigens to CTLs was influenced by the phase of vaccinia virus gene expression (Coupar et al., 1986). During the late phase of the virus replication cycle, and to some extent also during the early phase, partial or total inhibition of presentation of several influenza virus epitopes was observed (Townsend et al., 1988). Vaccinia virus-induced shutolf of cellular functions was discussed as a possible mechanism of the inhibition of antigen presentation. Because restoration of antigen recognition could be achieved by reducing the stability of influenza proteins, it was proposed, as an alternative explanation, that putative protease inhibitors encoded by vaccinia virus might be responsible for the observed inhibition of antigen processing.

Besides the replication-phase association, the inhibi- tory effect observed here for MCMV has little in common with the inhibitory effect described for vaccinia virus, and the mechanisms postulated there may not apply. First, MCMV does not induce a strong host shutoff, in particular not at the beginning of the early phase. Second, in comparison with the IE phase, when pp89 presentation was optimal, no alterations in pp89 stability were observed during the early phase, when presentation was blocked. For technical reasons, an MCMV recombinant expressing an unstable pp89 has not been constructed to date. If, as the data presented by Townsend et al. (1988) convincingly suggest, the rate of protein degradation governs antigen processing, then an accelerated catabolism of pp89 resulting in its processing before the inhibitory function has had time to operate would restore antigen presentation in cells infected with such an MCMV recombinant. This, however, would not explain the mechanism of interference with pp89 presentation. Third, the highly selective nature of the inhibition of pp89 antigen presentation is not compatible with the more general effect of protease inhibitors. Recently the human $C M V$, a virus closely related to MCMV, has been completely sequenced. Comparison of open reading frames coding for polypeptides of 300 amino acids and larger with available data bases has, unlike the example of vaccinia virus (Kotwal and Moss, 1989), revealed no detectable homology to known serine protease inhibitors (B. G. Barrell, personal communication). In summary, as opposed to the vaccinia virus system, a mechanism of inhibition that selectively affects pp89 must be proposed for MCMV.

An alternative mechanism that we considered is competition at the peptide level for binding to the Ld molecule. Related pp89-derived synthetic peptides, differing only in length and all containing the antigenic core sequence HFMPT, differ considerably in their antigenic potency, with the nonapeptide YPHFMPTNL having a very high affinity for $L^{d}$ (Reddehase et al., 1989). Since it is not known which of these peptides are actually generated in infected cells, it is highly possible that peptides derived from the early antigens E1 and E2 have a higher affinity for $L^{d}$. However, because simultaneous recognition of pp89, E1, and E2 was feasible in the late phase, peptide competition exerted by E1 or E2 is not a likely mechanism. It can be expected that, if pp89 were competed out by an unknown competitor stronger than $E 1$ and $E 2$, this competitor should also compete with E1 and E2. From all this, it appears that the number of $L^{d}$ molecules available for binding of peptides is not the limiting factor for $p p 89$ presentation. Finally, the fact that the inhibitory effect operated also in the $\mathrm{H}-2^{b}$ haplotype, in which the antigenic determinants of pp89 and of early antigens are most probably different from those presented by $L^{d}$, also disfavors competition.

In view of the evidence available, we hypothesize that inhibition of pp89 presentation is caused by a selective effect on pp89 exerted during the early phase by a viral protein or by a cellular factor induced by it. The selectivity of the effect may relate to the regulatory function of $\mathrm{pp89}$. As a mechanism, one could imagine complex formation with pp89 or an enzymatic activity exerted on pp89, either of 
which could prevent correct processing or transport to the cell surface. Studies with mutated pp89 may help to identify possible target sequences for the proposed interactions, and analysis of the genes transcribed during the first period of the early phase should contribute to the understanding of the underlying mechanism.

An interesting implication of our results is the fact that abundant expression of a protein of proven antigenicity in cells that express all molecules essential for antigen processing and presentation does not inevitably result in presentation of this antigen. It is worth considering that the presentation of certain cellular protein antigens may be subject to similar control mechanisms. Such regulatory mechanisms could add considerably to the complexity of selt/nonself discrimination.

Under the control of the immune system, CMV persists for life in the infected host in a state of latency that is associated with a block in viral gene expression, a characteristic of herpesviruses. For human CMV there is evidence that IE genes, but not late genes, are expressed in latently infected cells (Rice et al., 1984; Schrier et al., 1985). Since in human CMV the gene IE1 corresponding to gene iel of MCMV also codes for an immunodominant antigen for CTLs (Borysiewicz et al., 1988), it remains an unsolved question how latently infected cells expressing a protein of proven antigenicity can survive in the face of a specific $C T L$ response. The kind of negative regulation of antigen presentation documented here for MCMV could provide the solution for this paradox.

Experimental Procedures

\section{Mice}

BALB/c mice ( $\mathrm{H}-2^{d}$ haplotype), BALB/C-H-2dm2 mutant mice lacking $\mathrm{L}$ (Hansen et al., 1977), and C57BL/6 mice ( $\mathrm{H}-2^{\circ}$ haplotype) were bred in our own colony under specific-pathogen-free conditions.

\section{Cells and Viruses}

Third-passage MEFs were used for virus infection. The $L L^{d}$ line of $L$ fibroblasts $\left(H-2^{k}\right.$ haplotype), which is transfected with the gene for the MHC class I molecule $L^{d}$, and the Lfiet $L^{d}{ }^{d}$ line, which is transfected in addition with MCMV transcription unit iet, have been described previously (Koszinowski et al., 1967). MCMV of the strain Smith NR-194; American Type Culture Collection, Rockville. MD) was employed as tissue-culture-grown virus. The production of the recombinant vaccinia virus MCMV-iel-VAC, encoding pp89, has been reported before (Volkmer of al., 1987).

\section{Cytolytic Effector Cells}

Generation of MCMV-specific and pp89-specific polyclonal CTLs was achieved by in vitro restimulation with MCMV of spleen cells from mice that were latently infected with MCMV and infected with $1 \times 10^{8} \mathrm{PFU}$ of MCMV-iel-VAC 3 weeks before, respectivoly (Del Val et al., 1988). The Ld-restricted pp89-specific CTL clone IE1 (Feddehase of al. $1986 a, 1989$ ) and the $L^{0}$-specific CTL clone B6a $L^{\circ}$ (Reddehase ot al., 1986b) have been characterized previously. The $L^{d}$-restricted CTL clones E1 and E2, which are specific for MCMV early antigens, were cloned by limiting dilution from MCMV-specific polyclonal CTL cultures. Clones E1 and E2 were grown in medium containing $100 \mathrm{U} / \mathrm{m}$ recombinant human interleukin 2 (Sandoz Forschungsinstitut, Vienna, Austria), and restimulated weekly with MCMV and stimulator cells as described for clone IE1 (Reddehase et al., 1986a)

\section{Target Cells and Cytolytic Asans}

For selective and enthanced expression of IE genes, MEF were infected with 0.5 PFU of MCMV per cell by centrifugation ( $800 \times \mathrm{g}, 30 \mathrm{~min})$, which results in a multiplicity of intection of 10-20 (Reddehase et al.,
1984). Infection was performed in the presence of $\mathrm{CH}(50 \mu \mathrm{g} / \mathrm{ml})$, which was removed $3 \mathrm{hr}$ later by washing with medium containing act D ( 5 $\mu \mathrm{g} / \mathrm{ml})$. Limited early gene transcription after the $\mathrm{CH}$ treatment was achieved by removal of $\mathrm{CH}$ using in hibitor-free medium and by adding act $D$ to the final concentration of $5 \mu \mathrm{g} / \mathrm{ml}$ after the intervals indicated. The same metabolic inhibitor treatment was performed on Lie1- $L^{\circ}$ cells. Infection of MEF with MCMV-iel-VAC was done as with MCMV except that a multiplicity of 3 was used.

Restriction of gene expression to the IE and early phases of the MCMV replication cycle was achieved by infecting MEF with MCMV in the presence of PAA (250 $\mu \mathrm{g} / \mathrm{ml})$ to prevent viral DNA replication and late-phase gene expression.

Target cells were trypsinized and labeled for 90 min with $\mathrm{Na}_{2}^{51} \mathrm{CrO}_{4}$. and a standard $3 \mathrm{hr}$ cytolytic assay was performed with 1000 target cells and graded numbers of effector cells in 2-fold dilution steps. Data represent the mean percentage of specific lysis from three replicate cultures. For preparing target cells with exogenously added peptides, cells were incubated with peptides at a concentration of $100 \mu \mathrm{M}$ for 1 hr at $37^{\circ} \mathrm{C}$ after the ${ }^{51} \mathrm{Cr}$ labeling, followed by removal of excess peptide by washing the target cells before the addition of effector cells.

\section{Immunoprecipitation and Westem Blot Analysis}

Experiments were performed essentially as described (Keil et al., 1985). In brief, the same number of Lie1-Ld cels, uninfected MEF, and MEF infected with MCMV under the same conditions as used for target cell preparation were labeled with ${ }^{35}$ S]methionine in methionine-free medium for $20 \mathrm{~min}$, starting at 5,7 , and $9 \mathrm{hr}$ p.i. Cell lysates were immunoprecipitated with a murine antiserum to MCMV and analyzed by $10 \%$ polyacrylamide gel electrophoresis and autoradiogra phy. Westem blot analysis was performed with the same lysates, which, after separation by electrophoresis, were blotted onto a nitrocellulose membrane and incubated with the same antiserum.

Pulse-Laboling, Chase, and Nuclear/Cytoplasmic Fractionation Uninfected MEFs and MEFs infected with MCMV in the presence of CH were trypsinized at $3 \mathrm{hr}$ p.i., that is, immediately after $\mathrm{CH}$ removal, and labeled with [ ${ }^{35}$ SImethionine for $30 \mathrm{~min}$ in medium devoid of unlabeled methionine. Act $D$ was added at the incicated times. After the labeling period, cells were washed twice with medium containing a 2000-fold excess of unlabeled methionine, followed by tur ther incubation in medium containing the standard concentration of methionine. At given time points, aliquots were taken for the preparation of wholecell lysates and for the separation of nuclear and cytoplasmic fractions (Keil et al. 1985). This separation was achieved by resuspending the sedimented cells for $5 \mathrm{~min}$ in ice-cold buffer 1 (10 $\mathrm{mM}$ Tris- $\mathrm{HCl}$ [pH 8.5], $0.14 \mathrm{M} \mathrm{NaCl}, 1.5 \mathrm{mM} \mathrm{MgCl}, 0.5 \%$ Nonidet $\mathrm{P}-40$ ), followed by centrifugation $\left(800 \times 9,4^{\circ} \mathrm{C}, 5 \mathrm{~min}\right)$ through a custion of $24 \%$ sucrose in buffer 1 . Lysates were then prepared from the cytoplasmic fraction on top of the cushion and from the sedimented nuclei. Lysates were analyzed by immunoprecipitation and gel electrophoresis. A rabbit antiserum raised against the synthetic peptide $P(161-179)$ of pp89 coupled to bovine serum albumin as described (Det Val et al., 1988) was used for immunoprecipitation.

\section{Flow Cytofluorometry}

Uninfected MEFs and MCMV-infected MEFs were treated with $\mathrm{CH}$ and act $D$ following the protocol for target cell preparation. They were then incubated with the monocional antibodies B22-249 (Lemke of al.; 1979), 34.5.8S, and 31.3.4S (Cochet et al., 1986), specific for Lo, $D^{d}$, and $K^{\mathrm{d}}$, respectively, followed by fluorescein-conjugated $\left(\mathrm{F}(\mathrm{ab})_{2} \mathrm{frag}\right.$ ments of goat anti-mouse Ig $G$ antibodies (Jackson Immunoresearch Laboratories inc., West Grove, PA) and analyzed on a FACS IV as described (Reddehase et al., 1986a).

\section{Acknowledgments}

We thank A. Saalmüller and $H$.J. Bühring for help with flow cytofluorometry, A. Lüske and I. Huber for excellent technical assistance, and S. Grau and I. Bennett for the preparation of the manuscript. This work was supported by grants Ko $571 / 8$ and SFB 322 of the Deutsche Forschungsgemeinschaft. M. D. V. was the recipient of a grant from the Alexander von Humboldt Foundation.

The costs of publicetion of this article were defrayed in part by the 
payment of page charges. This article must therefore be hereby marked "actertisement" in accordance with 18 U.S.C. Section 1734 solely to indicate this fact.

Received November 18, 1988; revised April 7, 1989.

\section{Reterences}

Bernards, R., Schrier, P. I., Houweling, A., Bos, J. L., van der Eb, A. J., Zijlstra, M., and Melief, C. J. M. (1983). Tumorigenicity of cells transformed by adenovirus type 12 by evasion of T-cell immunity. Nature 305, 776-779.

Borysiewicz, L. K., Hickling, J. K., Graham, S., Sinclair, J., Cranage, M. P., Smith, G. L., and Sissions, J. G. P. (1988). Human cytomegalovirus-specific cytotoxic $T$ cells. Relative frequency of stage specific CTL recognizing the $72 \mathrm{kD}$ immediate early protein and glycoprotein B expressed by recombinant vaccinia virus. J. Exp. Med. 168, 919-932. Braciale, T. J., Morrison, L. A., Sweetser, M. T., Sambrook, J., Gething, M.J., and Braciale, V.L. (1987). Antigen presentation pathways to class I and class II MHC-restricted T lymphocytes. Immunol. Rev. 98, 95-114.

Burgert, H.G., and Kvist, S. (1985). An adenovirus type 2 glycoprotein blocks cell surface expression of human histocompatibility class I antigens. Cell 41, 987-997.

Cochet, M., Kast, W. M., Kummer, A. M., Transy, C., Melief, C. J. M., and Kourilsky, $P .(1986)$. Alternative splicing in the mouse $\mathrm{H}_{-2} \mathrm{~K}^{\mathrm{d}}$ gene is not necessary for the classical $K^{d}$ antigen lunction. Immunogenetics 24, 267-274.

Coupar, B. E., Andrew, M. E., Both, G. W., and Boyle, D. B. (1986). Temporal regulation of influenza hemagglutinin expression in vaccinia virus recombinants and effects on the immune response. Eur. J. Immunol. 16, 1479-1487.

Del Val, M., Volkmer, H., Rothbard, J. B., Jonjic, S., Messerle, M., Schickedanz, J., Reddehase, M. J., and Koszinowski, U. H. (1988). Molecular basis for cytolytic T lymphocyte recognition of the murine cytomegalovirus immediate-early protein pp89. J. Virol. 62, 3965-3972.

De Plaen, E., Lurquin, C., Van Pel, A., Mariamé, B., Szikora, J.P., Wöfel, T., Sibille, C., Chomez, P., and Boon, T. (1988). Immunogenic (tum ') variants of mouse tumor P815: cloning of the gene of tum " antigen P91A and identification of the tum ${ }^{-}$mutation. Proc. Natt. Acad. Sci. USA 85, 2274-2278.

Ebeling, A., Keil, G. M., Knust, E., and Koszinowski, U. H. (1983). Molecular cloning and physical mapping of murine cytomegalovirus DNA. J. Virol. 47, 421-433.

Germain, A. N. (1986). The ins and outs of antigen processing and presentation. Nature 332, 687-689.

Germain, R. N. (1988). Antigen processing and $\mathrm{CD}^{+} \mathrm{T}$ cell depletion in AIDS. Cell 54, 441-444.

Gooding, L. R. (1982). Characterization of a progressive tumor from $\mathrm{C} 3 \mathrm{H}$ fibroblasts transformed in vitro with SV40 virus. Immunoresistance in vivo correlates with phenotypic loss of $\mathrm{H}-2 \mathrm{~K}^{\mathrm{k}}$. J. Immunol. 129, 1306-1312.

Gregory, C. D., Murray, R. J., Edwards, C. F., and Rickinson, A. B. (1988). Downregulation of cell adhesion molecules LFA-3 and ICAM-1 in Epstein-Barr virus-positive Burkitt's lymphoma underlies tumor cell escape from virus-specific T cell surveillance. J. Exp. Med. 167, 1811-1824.

Haddada, H., Sogn, J. A., Coligan, J. E., Carbone, M., Dixon, K., Levine, A. S., and Lewis, A. M., Jr. (1988). Viral gene inhibition of class I major histocompatibility antigen expression: not a general mecha. nism governing the tumorigenicity of adenovirus type 2-, adenovirus type 12, and simian virus 40-transformed Syrian hamster cells. J. Virol. 62, 2755-2761.

Hansen, T. H., Cullen, S. E., Melvold, R., Kohn, H. I., Flaherty, L., and Sachs, D. H. (1977). Mutation in a new H-2 associated histocompatibility gene closely linked to H-2D. J. Exp. Med. 145, 1550-1558.

Jennings, S. R., Rice, P. L., Kloszewski, E. D., Anderson, A. W., Thompson, D. L., and Tevethia, S. S. (1985). Effect of herpes simplex virus types 1 and 2 on surface expression of class I major histocompatiblity complex antigens on infected cells. J. Virol. $56,757-766$.
Jonjic, S., Del Val, M., Keil, G. M., Reddehase, M. J., and Koszinowski, U. H. (1988). A nonstructural viral protein expressed by a recombinant vaccinia virus protects against lethal cytomegalovirus infection. J Virol. $62,1653-1658$

Keil, G. M., Ebeling-Keil, A., and Koszinowski, U. H. (1984). Temporal regulation of murine cytomegalovirus transcription and mapping of $\mathrm{vi}$ ral RNA synthesized at immediate early times after infection. J. Virol. 50, 784-795

Keil, G. M., Fibi, M. R., and Koszinowski, U. H. (1985). Characterization of the major immediate-early polypeptides encoded by murine cytomegalovirus. J. Virol. 54, 422-428.

Keil, G. M., Ebeling-Keil, A., and Koszinowski, U. H. (1987). Sequence and structural organization of murine cytomegalovirus immediateearly gene 1. J. Virol. 61, 1901-1908.

Koszinowski, U. H., Keil, G. M., Volkmer, H., Fibi, M. R., Ebeling-Keil, $A_{*}$, and Münch, K. (1986). The $89,000 \mathrm{M}_{\mathrm{f}}$ murine cytomegalovirus immediate-early protein activates gene transcription. J. Virol. 58, $59-66$.

Koszinowski, U. H., Keil, G. M., Schwarz, H., Schickedanz, J., and Reddehase, M. J. (1987). A nonstructural polypeptide encoded by immediate-early transcription unit 1 of murine cytomegalovirus is recognized by cytolytic T lymphocytes. J. Exp. Med. 166, 289-294.

Kotwal, G. J., and Moss, 8. (1989). Vaccinia virus encodes two proteins that are structurally related to members of the plasma serine protease inhibitor superfamily. J. Virol. 63,600-606.

Lemke, H., Hămmerling, G. J., and Hămmerling, U. (1979). Fine specificity analysis with monoclonal antibodies of antigens controlled by the major histocompatibility complex and by the Qa/TL region in mice. $1 \mathrm{~m}$. munol. Rev. 47, 175-206.

Lurquin, C., Van Pel, A., Mariamé, B., De Plaen, E., Szikora, J.-P., Janssens, C., Reddehase, M. J., Lejeune, J., and Boon, T. (1989). Structure of the gene coding for tum ${ }^{-}$antigen P91A: a peptide encoded by the mutated exon is recognized with Ld by cytolytic $T$ cells. Cell 58 , this issue.

Maryanski, J. L., Pala, P., Cerottini, J.C., and Corradin, G. (1987). Synthetic peptides as antigens and competitors in recognition by $\mathrm{H} \cdot 2$ restricted cytolytic T cells specific for HLA. J. Exp. Med. 167, 1391-1405.

Masucci, M. G., Torsteinsdottir, S., Colombani, J., Brautbar, C., Klein, E., and Klein, G. (1987). Down-regulation of ctass I HL.A antigens and of the Epstein-Barr virus-encoded latent membrane protein in Burkitt lymphoma lines. Proc. Natl. Acad. Sci. USA 84, 4567-4571.

Reddehase, M. J., and Koszinowski, U. H. (1984). Significance of herpesvirus immediate early gene expression in cellular immunity to cytomegalovirus infection. Nature $312,369-371$.

Reddehase, M. J., Keil, G. M., and Koszinowski, U. H. (1984). The cytoIytic T lymphocyte response to the murine cytomegalovirus. II. Detection of virus replication stage-specific antigens by separate populations of in vivo active cytolytic $\mathrm{T}$ lymphocyte precursors. Eur. $\mathrm{J}$. Immunol. 14, 56-61.

Reddehase, M. J., Bühring, H.J., and Koszinowski, U. H. (1986a). Cloned long-term cytolytic $T$ lymphocyte line with specificity for an immediate-early membrane antigen of murine cytomegalovirus. $\mathrm{J}$. Virol. $57,408-412$

Reddehase, M. J., Fibi, M. R., Keil. G. M. and Koszinowski, U. H. (1986b). Late-phase expression of a murine cytomegalovirus immediate-early antigen recognized by cytolytic $T$ lymphocytes. J. Virol. 60, 1125-1129.

Reddehase, M. J., Rothbard, J. B., and Koszinowski, U. H. (1989). A pentapeptide as minimal antigenic determinant for MHC class t-re. stricted T lymphocytes. Nature 337, 651-653.

Rice, G. P. A., Schrier, A. D., and Oldstone, M. B. A. (1984). Cytomegalovirus infects human lymphocytes and monocytes: virus expression is restricted to immediate-early gene products. Proc. Natl. Acad. Sci. USA 81, 6134-6138.

Schickendanz, J., Philipson, L., Ansorge, W., Pepperkok, P., Klein, R., and Koszinowski, U. H. (1988). The 89,000-Mr murine cytomegalovirus immediate-early protein stimulates c-fos expression and cellular DNA synthesis. J. Virol. 62, 3341-3347. 
Schrier, R. D., Nelson, J. A., and Oldstone, M. B. A. (1985). Detection of human cytomegalovirus in peripheral blood lymphocytes in a natural infection. Science 230, 1048-1051.

Schwartz, R. H. (1985). T-lymphocyte recognition of antigen in association with gene products of the major histocompatibility complex. Annu. Rev. Immunol. 3, 237-261.

Shimonkevitz, R., Kappler, J., Marrack, P., and Grey, H. (1983). Antigen recognition by $\mathrm{H}-2$ restricted $T$ cells. I. Cell free antigen processing. J. Exp. Med. 158, 303-316.

Stinski, M. F. (1983). Molecular biology of cytomegaloviruses. In The Herpesviruses, Vol. 2, B. Roizman, ed. (New York: Plenum Press), pp. 67-113.

Tanaka, K., Isselbacher, K. J., Khoury, G., and Jay, G. (1985). Reversal of oncogenesis by the expression of a major histocompatibility complex class I gene. Science 228, 26-30.

Townsend, A. R. M., Gotch, F. M., and Davey, J. (1985), Cytotoxic T cells recognize fragments of the influenza nucleoprotein. Cell 42, 457-467.

Townsend, A. A. M., Rothbard, J., Gotch, F. M., Bahadur, G., Wraith, D., and McMichael, A. J. (1986). The epitopes of influenza nucleoprotein recognized by cytotoxic $T$ lymphocytes can be defined with short synthetic peptides. Cell 44, 959-968.

Townsend, A. R. M., Bastin, J., Gould, K., Brownlee, G., Andrew, M., Coupar, B., Boyle, D. Chan, S., and Smith, G. (1988). Defective presentation to class I-restricted cytotoxic $T$ lymphocytes in vaccinia-infected cells is overcome by enhanced degradation of antigen. J. Exp. Med. 168, 1211-1224.

Vaessen, A. T. M. J., Houweling, A., and van der Eb, A. J. (1987). Posttranscriptional control of class I MHC mANA expression in adenovirus 12-transformed cells. Science 235, 1486-1488.

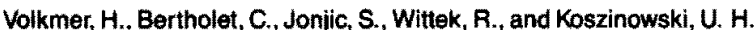
(1987). Cytolytic T lymphocyte recognition of the murine cytomegalovirus nonstructural immediate-early protein pp89 expressed by recombinant vaccinia virus. J. Exp. Med. 166, 668-677.

Yewdell, J. W., Bennink, J. R., Eager, K. B., and Ricciardi, R. P. (1988). CTL recognition of adenovirus-transformed cells infected with in fluenza virus: lysis by anti-influenza CTL parallels adenovirus-12 induced suppression of class I MHC molecules. Virology 162, 236238. 